Journal of Animal and Veterinary Advances 11 (14): 2576-2583, 2012

ISSN: $1680-5593$

(C) Medwell Journals, 2012

\title{
The Effects of MEM Vitamins and $\beta$-Mercaptoethanol on Porcine Embryonic Development, Reactive Oxygen Species and Apoptosis
}

\author{
Sang-Hyoun Park and Il-Jeoung Yu \\ Department of Theriogenology and Reproductive Biotechnologies, \\ College of Veterinary Medicine, Bio-Safety Research Institute, Chonbuk National University, \\ 561-756 Jeonju, Republic of Korea
}

\begin{abstract}
The objective of this study was to determine the synergistic effects of beta-Mercaptoethanol ( $\beta$-ME) and MEM vitamins (MEMv) as antioxidants supplemented into porcine maturation medium on maturation and Reactive Oxygen Species (ROS) of oocytes. In addition, the effects of $\beta$-ME and MEMv on subsequent embryonic development, ROS generation by embryos and apoptosis of blastocysts following In Vitro Fertilization (IVF), Chemical Activation (CA) and Electrical Activation (EA) were investigated. Cumulus-OocyteComplexes (COCs) were cultured in North Carolina State University (NCSU)-23 medium supplemented with $0.05 \times \mathrm{MEMv}, 25 \mu \mathrm{M} \beta-\mathrm{ME}$ and $25 \mu \mathrm{M} \beta-\mathrm{ME}$ and $0.05 \times \mathrm{MEMv}$, respectively. COCs cultured without $\beta-\mathrm{ME}$ and MEMv were regarded as control. Maturation rate and ROS levels of oocytes at $44 \mathrm{~h}$ of culture were assessed. Oocytes were fertilized in vitro or activated parthenogenetically and embryonic development and the ROS levels on 2 days of culture and the apoptosis levels of blastocyts were evaluated. Maturation rate of the $\beta$-ME and MEMv group was higher than that of the control group (86.0 03.6 vs. $73.3 \pm 1.1 \%$; p $<0.05$ ) although, ROS levels were not significantly different among the groups. Cleavage rate following IVF was increased in the $\beta-\mathrm{ME}$ and MEMv group compared to those of other groups and ROS levels of the $\beta$-ME and MEMv group were lower than those of the control group ( $6.9 \pm 0.2$ vs. $8.0 \pm 0.2 ; \mathrm{p}<0.05$ ). Blastocyst rate was increased in the $\beta$-ME and MEMv group compared to those of the control and MEMv groups $(\mathrm{p}<0.05)$. Conversely, the level of apoptosis

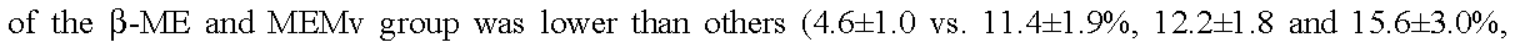
respectively; $\mathrm{p}<0.05$ ). Cleavage rate of the $\beta-\mathrm{ME}$ and $\mathrm{MEMv}$ group following $\mathrm{CA}$ was significantly higher compared with control while the ROS level was lower than the $\beta$-ME group (19.0 1.9 vs. $25.0 \pm 1.7$; $\mathrm{p}<0.05)$. The blastocyst formation rate of the $\beta-\mathrm{ME}$ and MEMv group was significantly increased than control while the level of apoptosis was lower than those of other groups (5.8 $1.2 \mathrm{vs.} 17.2 \pm 4.6 \%, 17.0 \pm 5.2$ and $22.6 \pm 3.2 \%$, respectively; $\mathrm{p}<0.05$ ). Embryonic developments following EA were not significantly different among the groups although, the ROS level of the $\beta$-ME and MEMv group was lower $(\mathrm{p}<0.05)$. In conclusion, addition of $\beta$-ME and MEM vitamins during porcine oocyte maturation was effective on subsequent embryonic development in IVF and CA by alleviating the influences of ROS generation and apoptosis.
\end{abstract}

Key words: $\beta$-mercaptoethanol, MEM vitamins, maturation rate, embryonic development, ROS, apoptosis, porcine oocyte

\section{INTRODUCTION}

Recent advances in new technologies to produce cloned and genetically modified pigs involve manipulating oocytes and/or embryos in vitro. Although, a great deal of progress has been made, the current In Vitro Production (IVP) systems still result in major problem (Gil et al., 2010). Oocyte maturation is a critical component of IVP systems for porcine embryos that have suffered from high incidence of polyspermy and poor quality
(Niwa, 1993; Wang and Niwa, 1995; Abeydeera and Day, 1997; Machaty et al., 1998; Gil et al., 2010). In particular, the oxidative stress in porcine oocytes might be caused by longer culture time in vitro than that in other mammalian animals (Long et al., 1994; Hunter and Greve, 1997). Many Reactive Oxygen Species (ROS) have a negative intracellular effect and suppress the fusion of sperm and oocyte and obstruct fertility and embryonic development of porcine oocytes (Aitken et al., 1993; De Lamirande et al., 1997; Olson and Seidel, 2000).

Corresponding Author: Il-Jeoung Yu, Department of Theriogenology and Reproductive Biotechnologies, College of Veterinary Medicine, Bio-Safety Research Institute, Chonbuk National University, 561-756 Jeonju, Republic of Korea 
Apoptosis is a process of programmed cell death that is induced by ROS and depletion of glutathione (Franco and Cidlowski, 2009). Apoptosis in preimplantation embryos can be induced by sub-optimal culture conditions in vitro and its incidence in developing embryos can be correlated to embryo quality (Betts and King, 2001; Levy et al., 2001).

Vitamins are important contributors to the development of mammalian embryo in vitro (Koo et al., 2008). Vitamins have been shown to improve embryo development in rabbit, hamster and sheep (Kane, 1988; Kane and Bavister, 1988; Gardner et al., 1994). Of the water soluble vitamins, the Vitamin B6 and niacin had the effect to reduce the oxidative stress level (Kamat and Devasagayam, 1996; Gardner et al., 1994; Olson and Seidel, 2000; Kannan and Jain, 2004). Bormann et al. (2003) showed that addition of Minimal Essential Medium vitamins (MEMv) during caprine oocyte maturation was beneficial for subsequent blastocyst development and viability. However, the effect of MEMv in porcine oocytes was limited depending on concentration of MEMv and oocyte maturation was not improved at any concentration (Naruse et al., 2007). Therefore, researchers were to seek a synergetic supplement as an antioxidant to improve porcine oocyte maturation and subsequently embryonic development in presence of MEMv.

Beta-Mercaptoethanol $(\beta-\mathrm{ME})$ has been demonstrated to protect against oxidative damage, particularly lipid peroxidation, both in vitro and in vivo (Wu et al., 1990; Forrest et al., 1994). This chemical may be effective on porcine oocytes which contain a much higher concentration of fatty acids compared to other species and may be more susceptible to lipid peroxidation (Am-in et al., 2011). Choe et al. (2010) demonstrated a synergistic effect of $\beta-\mathrm{ME}$ treatment during in vitro maturation on porcine embryonic development in North Carolina State University (NCSU)-23, a culture medium supplemented with cysteine.

Therefore, one of purposes was to determine a possible synergistic effect of the simultaneous addition of $\beta-\mathrm{ME}$ and MEMv on nuclear maturation in relation to ROS generation. In addition, to determine subsequent embryonic development in relation to ROS generations of early stage embryos and apoptosis of blastocyst in parthenogenetic activation and In Vitro Fertilization (IVF).

\section{MATERIALS AND METHODS}

Culture media: Unless otherwise noted, all chemicals and reagents used were purchased from Sigma-Aldrich (St. Louis, MO, USA). The medium used for collection and washing of porcine Oocyte Cumulus Complexes (COCs) was modified Tyrode's Lactate-HEPES Polyvinyl Alcohol (TL-HEPES-PVA) composed of $114 \mathrm{mMNaCl}, 3.2 \mathrm{mMKCl}$, $0.4 \mathrm{mMNa}_{2} \mathrm{H}_{2} \mathrm{PO}_{4}, 2 \mathrm{mM} \mathrm{CaCl} \cdot 2 \mathrm{H}_{2} \mathrm{O}, 0.5 \mathrm{mMMgCl} \cdot 6 \mathrm{H}_{2} \mathrm{O}$, $5 \mathrm{mM} \mathrm{NaHCO}_{3}, 20 \mathrm{mM}$ HEPES, $16.6 \mathrm{mM}$ sodium lactate (60\% syrup), $0.5 \%$ PVA, $10 \mathrm{IU} \mathrm{mL}^{-1}$ penicillin and $10 \mu \mathrm{g} \mathrm{mL} \mathrm{m}^{-1}$ streptomycin. Oocyte maturation was performed in NCSU-23 medium (Gil et al., 2007) supplemented with 10\% Porcine Follicular Fluid (PFF), $0.6 \mathrm{mM}$ cysteine, $10 \mathrm{ng} \mathrm{mL}^{-1}$ Epidermal Growth Factor (EGF), $10 \mathrm{IU} \mathrm{mL}^{-1}$ Pregnant Mare Serum Gonadotropin (PMSG) and $10 \mathrm{~T} \mathrm{~mL}^{-1}$ Human Chorionic Gonadotropin (HCG). PFF was collected from ovarian follicles that ranged from $3-6 \mathrm{~mm}$ in diameter by centrifugation at $1,600 \times \mathrm{g}$ for $30 \mathrm{~min}$ at room temperature and filtration through a $1.2 \mu \mathrm{m}$ syringe filter. The final product was stored at $-20^{\circ} \mathrm{C}$ until use. Fertilization medium, based on modified Tris-buffered medium (mTBM; $113.1 \mathrm{mM} \mathrm{NaCl}$, $3 \mathrm{mM} \mathrm{KCl}, 7.5 \mathrm{mM} \mathrm{CaCl}_{2} \cdot 2 \mathrm{H}_{2} \mathrm{O}, 20 \mathrm{mM}$ Tris (Trizma Base), $11 \mathrm{mM}$ D-glucose and $5 \mathrm{mM}$ sodium pyruvate) was supplemented with $2 \mathrm{mM}$ caffeine and $0.2 \%$ Bovine Serum Albumin (BSA). In Vitro Culture 1 (IVC 1) was composed of D-glucose-free NCSU-23 supplemented with $0.17 \mathrm{mM}$ sodium pyruvate, $2.73 \mathrm{mM}$ sodium lactate (60\% syrup) and $0.4 \%$ BSA. In Vitro Culture 2 (IVC 2) was NCSU-23 containing $0.4 \% \mathrm{BSA}$.

Oocyte collection and In Vitro Maturation (IVM): Porcine ovaries were collected from a local abattoir and transported to the laboratory at $34-36^{\circ} \mathrm{C}$ in $0.9 \%$ saline supplemented with $100 \Pi \mathrm{mL}^{-1}$ penicillin $\mathrm{G}$ and $100 \mu \mathrm{g} \mathrm{mL}^{-1}$ streptomycin. COCs were aspirated through an 18-gauge needle. Oocytes with compact cumulus mass and a dark, evenly graduated cytoplasm were washed three times in TL-HEPES-PVA media and maturation media, respectively. COCs were randomly allocated to maturation medium with $0.05 \times \mathrm{MEMv}, 25 \mu \mathrm{M} \beta-\mathrm{ME}$ and $0.05 \times \mathrm{MEMv}$ and $25 \mu \mathrm{M} \beta-\mathrm{ME}$, respectively. COCs (20 25) were cultured in a $100 \mu \mathrm{L}$ droplet of maturation medium supplemented with $10 \mathrm{IU} \mathrm{mL}^{-1}$ PMSGand $10 \mathrm{IU} \mathrm{mL}^{-1} \mathrm{HCG}$ for $22 \mathrm{~h}$ and then for another $22 \mathrm{~h}$ in maturation medium without hormones. COCs cultured without MEMv and $\beta-\mathrm{ME}$ were regarded as control. Oocyte maturation was carried out under sterile mineral oil at $39^{\circ} \mathrm{C}$ in a humidified atmosphere of $5 \% \mathrm{CO}_{2}$ in air.

Sperm preparation and In Vitro Fertilization (IVF): Extended spermatozoa supplied by Irae Yangdon were maintained at $17^{\circ} \mathrm{C}$. Percoll solutions and gradients were prepared as described previously ( $Y u$ et al., 2002). A twolayer discontinuous gradient was formed by layering $1 \mathrm{~mL}$ of a $45 \%$ Percoll solution on top of $1 \mathrm{~mL}$ of a $90 \%$ Percoll 
solution in a $15 \mathrm{~mL}$ conical tube. Aliquants of extended semen $(3 \mathrm{~mL})$ were layered onto the Percoll gradient and centrifuged for $20 \mathrm{~min}$ at $850 \times \mathrm{g}$ at room temperature. The pellet recovered after aspiration of the supernatant was washed two times by centrifugation with $5 \mathrm{~mL}$ Dulbecco's Phosphate Buffered Saline (D-PBS) supplemented with $0.1 \% \mathrm{BSA}, 10 \mathrm{IU} \mathrm{mL} \mathrm{mL}^{-1}$ penicillin and $10 \mu \mathrm{g} \mathrm{mL}$ streptomycin at $350 \times \mathrm{g}$ for $3 \mathrm{~min}$.

After the supernatant was discarded, motile spermatozoa were collected. Sperm concentration (spermatozoa $\mathrm{mL}^{-1}$ ) was adjusted to $10 \times 10^{5}$ by dilution with mTBM. Oocytes with expanded cumulus cells were treated with $1 \mathrm{mg} \mathrm{mL}^{-1}$ hyaluronidase in TL-HEPES-PVA and were denuded by gentle aspiration with a small-bore glass pipette. The denuded oocytes were washed three times with mTBM and transferred to an mTBM insemination drop $(45 \mu \mathrm{L})$ overlaid with mineral oil (20-25 oocytes per drop). A $5 \mu \mathrm{L}$ volume of spermatozoa was added to each insemination drop to give a final concentration of $1 \times 10^{5}$ spermatozoa/mL. Oocytes and spermatozoa were co-cultured for $6 \mathrm{~h}$ at $39^{\circ} \mathrm{C}$ in a humidified atmosphere of $5 \% \mathrm{CO}_{2}$ in air.

Parthenogenetic Activation (PA): Following IVM, cumulus cells were removed by repeated pipetting in TLHEPES supplemented with $0.3 \%$ hyaluronidase. For Chemical Activation (CA), oocytes were incubated in IVC 1 medium containing $5 \mu \mathrm{M}$ calcium ionophore for $5 \mathrm{~min}$, washed twice and incubated for $3 \mathrm{~h}$ in NCSU-23 medium supplemented with $2.0 \mathrm{mM} 6$ D-Methyl Amino Purine (6 D-MAP). For Electrical Activation (EA), oocytes were transferred to pulsing medium consisting of $0.3 \mathrm{M}$ D-mannitol, $0.1 \mathrm{mM} \mathrm{MgSO}_{4}, 0.05 \mathrm{mM} \mathrm{CaCl}_{2}$ and $0.01 \%$ $\mathrm{PVA}$, washed three times and then transferred to a chamber containing two electrodes overlaid with pulsing medium. The oocytes were then stimulated with a direct current-pulse of $1.5 \mathrm{kV} \mathrm{cm}^{-1}$ for a duration of $100 \mu \mathrm{sec}$ using a BTX Electro-Cell Manipulator 2001 (BTX, San Diego, CA, USA). After activation, oocytes were washed and transferred into $500 \mu \mathrm{L}$ of culture media covered with mineral oil.

In vitro culture: Following either $\mathrm{PA}$ or IVF, presumptive zygotes were washed three times, transferred to $50 \mu \mathrm{L}$ roplets (15-20 presumptive zygotes per drop) of IVC 1 medium and incubated for 2 days at $39^{\circ} \mathrm{C}$ in a humidified atmosphere of $5 \% \mathrm{CO}_{2}$ in air. After 2 days of embryo culture, cleavage formation was assessed. Embryos were then washed twice, transferred to $50 \mu \mathrm{L}$ droplets of IVC 2 medium and incubated for 6 days after which the blastocyst formation was assessed.
Assessment of oocyte meiotic stage: Ocytes denuded by vigorous shaking in 3\% sodium citrate solution were fixed in a 4 well culture dish (Nunc, Rochester, NY, USA) containing $500 \mu \mathrm{L}$ of ethanol:acetic acid $(3: 1, \mathrm{v} / \mathrm{v})$ for $48 \mathrm{~h}$. They were then dispensed on to a slide to which a coverslip was added. Each sample was stained with aceto-orcein $(1 \%(\mathrm{w} / \mathrm{v})$ orcein in $45 \%(\mathrm{v} / \mathrm{v})$ acetic acid) and destained with glycerol:acetic acid:distilled water $(1: 1: 3, \mathrm{v} / \mathrm{v})$. Oocytes were evaluated under a light microscope at 400x magnification. Meiotic stages were classified as previously described (Romar and Funahashi, 2006) as germinal vesicle, germinal vesicle breakdown, Metaphase I, Anaphase I, Telophase I, or Metaphase II.

Measurement of reactive oxygen species contents: The levels of ROS in the oocytes and embryos were examined according to the Diclorohydrofuorescein Dacetate (DCHFDA) Method described by Hashimoto et al. (2000). Briefly, oocytes after maturation and only cleaved embryos at day 2 of culture were selected, respectively and transferred into IVC 1 medium containing $10 \mu \mathrm{M}$ DCHFDA. After 30 min of culture, oocytes and embryos were washed in PVA-DPBS. The respective fluorescent emissions from oocytes and embryos were recorded as TIFF files using a cooled CCD camera attached to a fluorescence microscope (Axio, Carl Zeiss, Goettingen, Germany) with filters at $405-435 \mathrm{~nm}$ for excitation and at $515 \mathrm{~nm}$ for emission. The recorded fluorescent images were analyzed using ImageJ software $1.33 \mu$ (National Institutes of Health, Bethesda, MD, USA) by the intensity of fluorescence in each oocyte and embryo picture.

Assessment of cell numbers in blastocyst: Blastocysts were stained in $500 \mu \mathrm{L}$ of Hoechst $33342\left(5 \mu \mathrm{g} \mathrm{mL}^{-1}\right)$ in TL-HEPES-PVA for $15 \mathrm{~min}$ at room temperature, mounted on slides and covered with cover slips. Cell numbers in blastocyst were determined using a fluorescent inverted microscope (Nikon, Tokyo, Japan).

\section{Detection of apoptosis by terminal deoxynucleotidyl Transferase-Mediated d-UTP Nick End-Labeling} (TUNEL) assay: The degree of apoptosis was assessed in the selected blastocysts by the following procedures described previously (Cui and Kim, 2005). Briefly, after washing three times in PBS supplemented with PVA $\left(1 \mathrm{mg} \mathrm{mL}^{-1}\right.$ ), the embryos at the blastocysts were fixed in $4 \%$ paraformaldehyde in PBS without $\mathrm{Ca}^{2}$ and $\mathrm{Mg}^{2}(-)$ for $1 \mathrm{~h}$ at room temperature. Then, the embryos were washed three times in PBS (-)/PVA and permeabilized by incubation in $0.5 \%$ Triton X-100 in PBS for $1 \mathrm{~h}$ at $4^{\circ} \mathrm{C}$. 
After permeabilization, blastocysts were washed 3 times in PBS (-)/PVA and incubated with a fluoresceinconjugated TUNEL assay kit (In Situ Cell Death Detection kit, Roche; Mannheim, Germany) in the dark for $1 \mathrm{~h}$ at $39^{\circ} \mathrm{C}$.

The blastocysts were then counterstained with $40 \mu \mathrm{g} \mathrm{mL} \mathrm{m}^{-1}$ Propidium Iodide (PI) in order to visualize the total cell number. The numbers of TUNEL-positive and total cells in the blastocysts were determined from an optical image of whole-mount embryos under fluorescence microscopy (Axio, Carl Zeiss, Goettingen, Germany). The percentage of TUNEL-positive cells is described as the percentage of TUNEL-positive cells relative to the total number of cells.

Statistical analysis: Four replicates were conducted for each experiment. Percentage data were subjected to an arcsin transformation before analysis. All data and data sets are presented as the mean \pm SEM and were analyzed by Duncan's multiple range test using the Statistical Analysis System Ver. 8x (SAS, Cary, NC and USA). For all analyses, $\mathrm{p}<0.05$ was considered significant.

\section{RESULTS AND DISCUSSION}

Effects of $\beta$-ME and MEMv on maturation and ROS generation of oocytes: Maturation rate of oocytes into metaphase II in the group treated with $\beta$-ME and MEMv was higher than that of the control $(86.0 \pm 3.6$ vs. $73.3 \pm 1.1 \%$; Table $1 ; \mathrm{p}<0.05$ ). However, the levels of ROS were not significantly different among groups.
Effects of $\beta$-ME and MEMv on development, ROS generation and apoptosis in porcine embryos following IVF: Cleavage formation, blastocyst formation, ROS generation of cleaved embryos and apoptosis of blastocyst following IVF are shown in Table 2. Cleavage formations were not significantly different among groups, although the $\beta-\mathrm{ME}$ and MEMv group showed the highest cleavage rate $(81.7 \pm 4.8 \%)$. The blastocyst rate of the $\beta-\mathrm{ME}$ and MEMv group was higher than those of the control and MEMv groups ( $36.1 \pm 2.1$ vs. $24.9 \pm 2.6 \%$ and $24.5 \pm 3.1 \%$, respectively; $\mathrm{p}<0.05$ ). Cell numbers of blastocyst were not significantly different among groups. The combination of $\beta-\mathrm{ME}$ and MEMv reduced ROS generation by cleaved embryos compared with the levels in the control group and MEMv group (6.9 10.2 vs. $8.0 \pm 0.2$ and 7.6 \pm 0.1 , respectively; Fig. $1 \mathrm{a} ; \mathrm{p}<0.05$ ). In addition, the level of ROS in the $\beta-M E$ and MEMv group was similar to that of the $\beta-\mathrm{ME}$ group $(6.9 \pm 0.2$ vs. $6.8 \pm 0.1)$. The rate of TUNEL-positive cells in the $\beta$-ME and MEMv group was lower than those of other groups ( $4.6 \pm 1.0$ vs. $11.4 \pm 1.9 \%$, $12.2 \pm 1.8$ and $15.6 \pm 3.0 \%$, respectively; $\mathrm{p}<0.05$ ).

Effects of $\beta-M E$ and MEMv on development, ROS generation and apoptosis in porcine embryos following CA: Cleavage formation, blastocyst formation, ROS generation of cleaved embryos and apoptosis of blastocyst following CA are shown in Table 3. Cleavage rate in the $\beta-\mathrm{ME}$ and $\mathrm{MEMv}$ group was greater than that seen in the absence of antioxidant ( $80.9 \pm 2.7$ vs. $71.0 \pm 3.1 \% ; \mathrm{p}<0.05$ ). Blastocyst rate in the $\beta-\mathrm{ME}$ and MEMv group was higher than that of the control group

Table 1: Effects of $\beta$-ME and MEMv in maturation medium on maturation rate and Reactive Oxygen Species (ROS) in porcine oocytes

\begin{tabular}{|c|c|c|c|c|}
\hline \multirow[b]{2}{*}{ Groups $^{a}$} & \multicolumn{2}{|l|}{ Maturation rate ${ }^{b}$} & \multicolumn{2}{|l|}{$\operatorname{ROS}^{c}$} \\
\hline & No. of oocytes & Oocytes matured toMII stage (\%) & No. of oocytes & Levels (intensity/oocytes) \\
\hline Control & 121 & $73.3 \pm 1.1^{\mathrm{b}}$ & 40 & $7.8 \pm 0.5$ \\
\hline MEMv & 142 & $80.2 \pm 6.0^{\mathrm{a}, \mathrm{b}}$ & 44 & $8.3 \pm 0.3$ \\
\hline$\beta-\mathrm{ME}$ & 104 & $82.4 \pm 5.2^{\mathrm{ab}}$ & 63 & $7.8 \pm 0.4$ \\
\hline 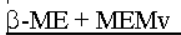 & 147 & $86.0 \pm 3.6^{\mathrm{a}}$ & 68 & $7.1 \pm 0.4$ \\
\hline
\end{tabular}

Within the column, values with different letters (a and b) are different $\left(\mathrm{p}<0.05\right.$ ). ${ }^{\mathrm{a}} \mathrm{Control}$ : Absence of $\beta$-mercaptoethanol and MEM vitamins; MEMv: $0.05 \times$ MEM vitamins; $\beta$-ME: $25 \mu \mathrm{M} \beta$-Mercaptoethanol; $\beta$-ME + MEMv: $25 \mu \mathrm{M} \beta$-Mercaptoethanol and $0.05 \times$ MEM vitamins. ${ }^{b}$ Maturation rate: the rate of metaphase II after culture of oocytes for $44 \mathrm{~h}$. ${ }^{\circ}$ Levels of ROS were assessed after culture of oocytes for $44 \mathrm{~h}$. Data are expressed as mean \pm SEM

Table 2: Effects of $\beta$-ME and MEMv in maturation medium on developmental competence, generation of Reactive Oxygen Species (ROS) and apoptosis in porcine embryos following IVF

\begin{tabular}{|c|c|c|c|c|c|c|}
\hline Groups $^{\mathrm{a}}$ & $\begin{array}{l}\text { No. of } \\
\text { oocytes }\end{array}$ & $\begin{array}{c}\text { Cleavage } \\
\text { rates }^{b}(\%, n)\end{array}$ & $\begin{array}{l}\text { Blastocyst } \\
\text { rates }^{c}(\%, n)\end{array}$ & $\begin{array}{l}\text { No. of cells } \\
\text { in blastocyst (n) }\end{array}$ & $\begin{array}{l}\text { Level of } \\
\operatorname{ROS}^{b}(n)\end{array}$ & $\begin{array}{c}\text { TUNEL-positive } \\
\text { nucleic }^{c}(\%, n)\end{array}$ \\
\hline Control & 199 & $76.5 \pm 3.9(151)$ & $24.9 \pm 2.6^{b}(49)$ & $33.9 \pm 8.1(49)$ & $8.0 \pm 0.2^{a}(47)$ & $11.4 \pm 1.9^{9}(17)$ \\
\hline MEMv & 200 & $74.9 \pm 4.3(150)$ & $24.5 \pm 3.1^{\mathrm{b}}(49)$ & $34.4 \pm 11.1$ (49) & $7.6 \pm 0.1^{\mathrm{a}}(46)$ & $12.2 \pm 1.8^{\mathrm{a}}(19)$ \\
\hline$\beta-\mathrm{ME}$ & 196 & $75.3 \pm 2.8(148)$ & $30.2 \pm 2.5^{\mathrm{a}, \mathrm{b}}(59)$ & $30.6 \pm 8.2(59)$ & $6.8 \pm 0.1^{b}(42)$ & $15.6 \pm 3.0^{\mathrm{a}}(22)$ \\
\hline$\beta-\mathrm{ME}+\mathrm{MEMv}$ & 205 & $81.7 \pm 4.8(168)$ & $36.1 \pm 2.1^{\mathrm{a}}(74)$ & $35.0 \pm 6.0(74)$ & $6.9 \pm 0.2^{b}(31)$ & $4.6 \pm 1.0^{b}(32)$ \\
\hline
\end{tabular}

Within the same column, values with different letters (a and $b$ ) are different $(p<0.05)$. ${ }^{a} \mathrm{Control}$ : Absence of $\beta$-mercaptoethanol and MEM vitamins; MEMv: $0.05 \times$ MEM vitamins; $\beta$-ME: $25 \mu \mathrm{M} \beta$-Mercaptoethanol; $\beta$-ME + MEMv: $25 \mu \mathrm{M} \beta$-Mercaptoethanol and $0.05 \times$ MEM vitamins. ${ }^{b}$ Cleavage rates and levels of ROS (intensity of embryos) were assessed on day 2 of culture. 'Blastocyst rates and levels of apoptosis in blastocyst were assessed on day 8 of culture. Data are expressed as mean \pm SEM 
Table 3: Effects of $\beta$-ME and MEMv in maturation medium on developmental competence, generation of Reactive Oxygen Species (ROS) and apoptosis in porcine embry os following chemical activation

\begin{tabular}{|c|c|c|c|c|c|c|}
\hline Groups $^{a}$ & $\begin{array}{l}\text { No. of } \\
\text { oocytes }\end{array}$ & $\begin{array}{l}\text { Cleavage } \\
\text { rates }^{b}(\%, n)\end{array}$ & $\begin{array}{l}\text { Blastocyst } \\
\text { rates }^{c}(\%, n)\end{array}$ & $\begin{array}{l}\text { No. of cells } \\
\text { in blastocyst (n) }\end{array}$ & $\begin{array}{l}\text { Level of } \\
\operatorname{ROS}^{b}(n)\end{array}$ & $\begin{array}{c}\text { TUNEL-positive } \\
\text { nucleic }(\%, n)\end{array}$ \\
\hline Control & 186 & $71.0 \pm 3.1^{\mathrm{b}}(131)$ & $13.3 \pm 2.4^{b}(24)$ & $11.9 \pm 5.2(24)$ & $23.0 \pm 2.9^{a b}(23)$ & $17.2 \pm 4.6^{a}(14)$ \\
\hline MEMv & 217 & $76.3 \pm 2.4^{\mathrm{a}, \mathrm{b}}(165)$ & $16.1 \pm 2.1^{\mathrm{a}, \mathrm{b}}$ & $23.8 \pm 16.6(35)$ & $18.0 \pm 1.3^{b}(31)$ & $17.0 \pm 5.2^{\mathrm{a}}(11)$ \\
\hline$\beta-\mathrm{ME}$ & 205 & $74.2 \pm 2.7^{\mathrm{a}, \mathrm{b}}(152)$ & $17.8 \pm 3.5^{\mathrm{a}, \mathrm{b}}$ & $16.7 \pm 7.1(36)$ & $25.0 \pm 1.7^{\mathrm{a}}(29)$ & $22.6 \pm 3.2^{\mathrm{a}}(17)$ \\
\hline$\beta-M E+M E M v$ & 227 & $80.9 \pm 2.7^{\mathrm{a}}(184)$ & $25.5 \pm 4.6^{\mathrm{a}}(58)$ & $19.1 \pm 8.7(58)$ & $19.0 \pm 1.9^{b}(22)$ & $5.8 \pm 1.2^{\mathrm{b}}(20)$ \\
\hline
\end{tabular}

Within the same column, values with different letters ( $\mathrm{a}$ and $\mathrm{b}$ ) are different $(\mathrm{p}<0.05)$. ${ }^{\mathrm{a}} \mathrm{Control}$ : Absence of $\beta$-mercaptoethanol and MEM vitamins; $\mathrm{MEMv}$ : $0.05 \times$ MEM vitamins; $\beta$-ME: $25 \mu \mathrm{M} \beta$-Mercaptoethanol; $\beta$-ME + MEMv: $25 \mu \mathrm{M} \beta$-Mercaptoethanol and $0.05 \times$ MEM vitamins. ${ }^{b} \mathrm{Cleavage}$ rates and levels of ROS (intensity of embryos) were assessed on day 2 of culture. ${ }^{c}$ Blastocyst rates and levels of apoptosis in blastocyst were assessed on day 8 of culture. Data are expressed as mean \pm SEM

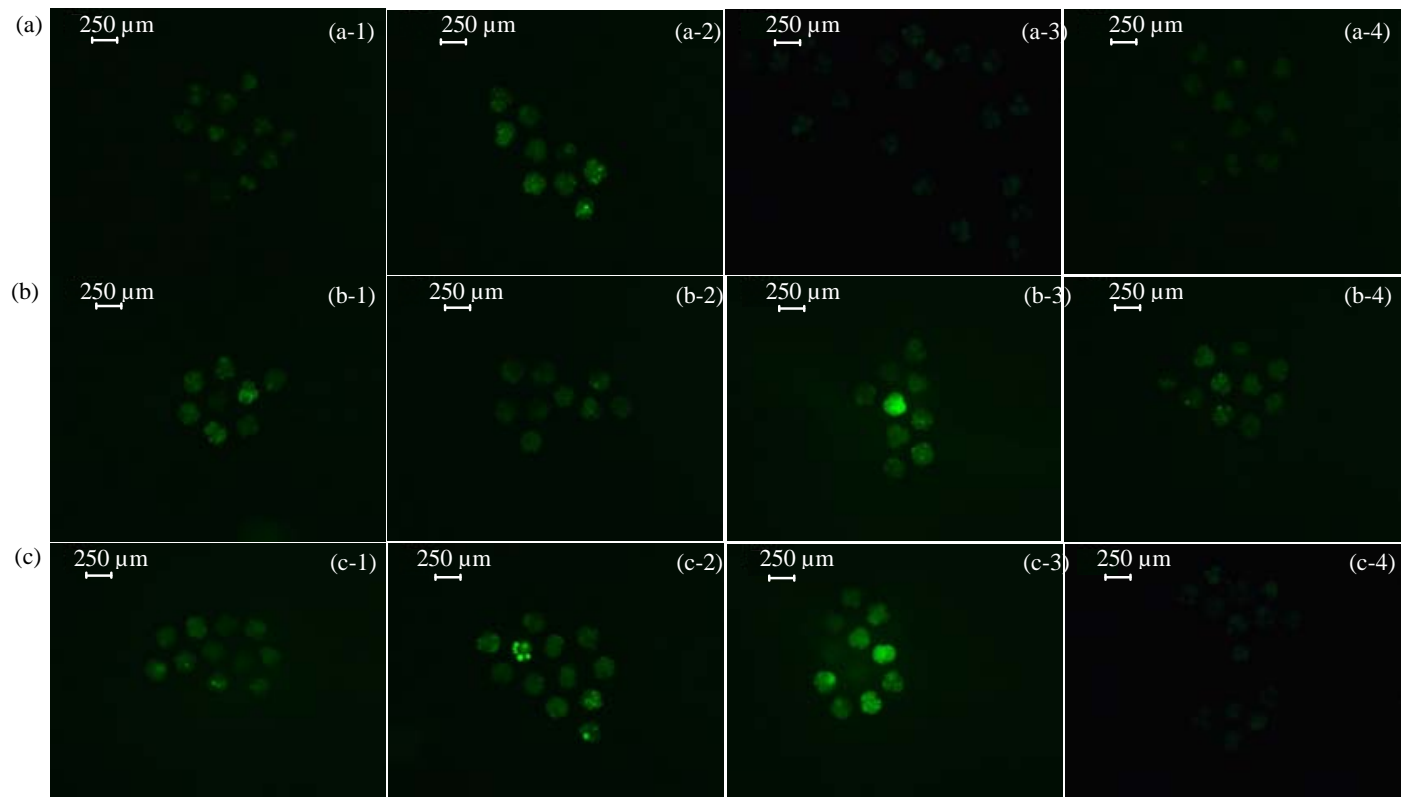

Fig. 1: Images of DCHFDA staining representing the intracellular ROS levels of cleaved embryos on day 2 of culture following In Vitro Fertilization(IVF), Chemical Activation (CA) or Electrical Activation (EA). IVF (a): Control (a-1),

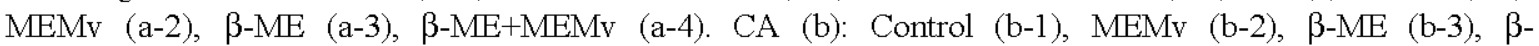

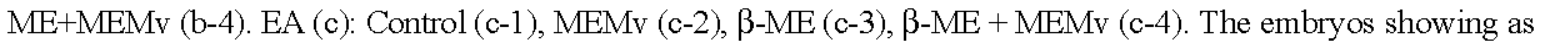
brighter green have higher levels of intracellular ROS. Control: absence of $\beta$-mercaptoethanol and MEM vitamins; MEMv: $0.05 \times \mathrm{MEM}$ vitamins; $\beta$-ME: $25 \mu \mathrm{M} \beta$-mercaptoethanol; $\beta$-ME+MEMv: $25 \mu \mathrm{M} \beta$-mercaptoethanol and $0.05 \times$ MEM vitamins. Magnification: $50 \mathrm{x}$

(25.5 \pm 4.6 vs. $13.3 \pm 2.4 \%$; p $<0.05)$. Cell numbers of blastocyst were not significantly different among groups. The combination of $\beta-\mathrm{ME}$ and MEMv reduced ROS generation compared to that in the $\beta$-ME group $(19.0 \pm 1.9$ vs. $25.0 \pm 1.7$; Fig $1 \mathrm{~b} ; \mathrm{p}<0.05$ ). The ROS level of the $\beta-\mathrm{ME}$ and MEMv group was similar to that of the MEMv group (19.0 \pm 1.9 vs. 18.0 \pm 1.3 ). The rate of TUNEL-positive cells in the $\beta$-ME and MEMv group was lower than those of other groups $(5.8 \pm 1.2$ vs. $17.2 \pm 4.6 \%, 17.0 \pm 5.2$ and $22.6 \pm 3.2 \%$, respectively; $\mathrm{p}<0.05$ ).

Effects of $\beta$-ME and MEMv on development, ROS generation and apoptosis in porcine embryos following EA: Cleavage formation, blastocyst formation, ROS generation of cleaved embryos and blastocyst apoptosis following EA are shown in Table 4. Cleavage formations of oocytes activated electrically were not significantly different among groups. The blastocyst formations and cell numbers were not significantly different among groups. The ROS level in the $\beta$-ME and MEMv group was lower than those of the other groups $(14.3 \pm 1.1$ vs. $20.5 \pm 1.3,22.8 \pm 1.5$ and $20.8 \pm 1.4$, respectively; Fig $1 \mathrm{c}$; $\mathrm{p}<0.05$ ). The rates of TUNEL-positive cells were not significantly different among groups.

In the present study, one of the purposes was to demonstrate synergetic effects of $\beta-\mathrm{ME}$ and MEMv as antioxidants on the maturation and ROS generation of porcine oocytes. The combination of $\beta$-ME and MEMv supplemented into maturation medium significantly increased the maturation rate of oocytes compared to that 
Table 4: Effects of $\beta$-ME and MEMv in maturation medium on developmental competence, generation of Reactive Oxygen Species (ROS) and apoptosis in porcine embry os following electrical activation

\begin{tabular}{|c|c|c|c|c|c|c|}
\hline Groups $^{\mathrm{a}}$ & $\begin{array}{l}\text { No. of } \\
\text { oocytes }\end{array}$ & $\begin{array}{c}\text { Cleavage } \\
\text { rates }^{b}(\%, n)\end{array}$ & $\begin{array}{c}\text { Blastocyst } \\
\operatorname{rates}^{c}(\%, n)\end{array}$ & $\begin{array}{l}\text { No. of cells } \\
\text { in blastocyst (n) }\end{array}$ & $\begin{array}{l}\text { Level of } \\
\operatorname{ROS}^{b}(n)\end{array}$ & $\begin{array}{c}\text { TUNEL-positive } \\
\text { nucleic }^{c}(\%, n)\end{array}$ \\
\hline Control & 141 & $85.9 \pm 1.2(121)$ & $14.8 \pm 2.1(20)$ & $12.9 \pm 1.9(20)$ & $20.5 \pm 1.3^{\mathrm{a}}(24)$ & $17.6 \pm 7.5(17)$ \\
\hline MEMV & 177 & $85.9 \pm 1.6(152)$ & $18.0 \pm 2.0(31)$ & $16.3 \pm 2.2(31)$ & $22.8 \pm 1.5^{\mathrm{a}}(36)$ & $12.0 \pm 4.1(14)$ \\
\hline$\beta-\mathrm{ME}$ & 176 & $85.7 \pm 2.9(151)$ & $16.0 \pm 3.5(27)$ & $15.3 \pm 2.0(27)$ & $20.8 \pm 1.4^{a}(31)$ & $9.4 \pm 2.2(15)$ \\
\hline$\beta-\mathrm{ME}+\mathrm{MEMv}$ & 172 & $90.3 \pm 2.9(157)$ & $20.4 \pm 1.6(35)$ & $15.2 \pm 2.3(35)$ & $14.3 \pm 1.1^{\mathrm{b}}(31)$ & $7.2 \pm 3.5(16)$ \\
\hline
\end{tabular}

Within the same column, values with different letters (a and b) are different ( $<<0.05$ ). ${ }^{a}$ Control: Absence of $\beta$-mercaptoethanol and MEM vitamins; MEMv: $0.05 \times$ MEM vitamins; $\beta$-ME: $25 \mu \mathrm{M} \beta$-Mercaptoethanol; $\beta$-ME+MEMv: $25 \mu \mathrm{M} \beta$-Mercaptoethanol and $0.05 \times$ MEM vitamins. ${ }^{b} \mathrm{Cleavage}$ rates and levels of ROS (intensity of embryos) were assessed on day 2 of culture. ${ }^{c}$ Blastocyst rates and levels of apoptosis in blastocyst were assessed on day 8 of culture

of the control in this study. Naruse et al. (2007) presented that the maturation rate of porcine oocytes treated with MEMv was similar to that of the control group without MEMv. Kobayashi et al. (2006) also demonstrated that the $\mathrm{MII}$ rate of porcine oocytes in a $\beta$-ME group was similar to those of groups without $\beta$-ME. On the other hand, maturation rates of oocytes were not directly related to $\mathrm{ROS}$ reduction by antioxidants. In vitro culture results in higher oxygen concentration than in vivo environments, leading to an increased level of ROS (Luvoni et al., 1996). The antioxidant requirements are varied during IVM, IVF and IVC although, antioxidants are beneficial additives to synthetic culture media as ROS scavengers (Choe et al., 2010). Researchers infer that the process of oocyte maturation in vitro might generate less ROS compared to in vitro fertilization and in vitro culture of embryos. The levels of ROS might not be as influenced by antioxidants as researchers had expected. In addition, maturation rate was determined by assessing $\mathrm{MII}$ rate while ROS of oocytes were assessed after culture for $44 \mathrm{~h}$. Researchers can also speculate that the levels of ROS in the $\beta$-ME and MEMv group might be diluted by other oocytes at different nuclear stage which might generate more or less ROS.

Researchers understood that nuclear maturation rate according to antioxidants was consecutively related to cleavage rate of oocytes following IVF or CA. $\beta-\mathrm{ME}$ and MEMv treatment during oocyte maturation increased cleavage formation of oocytes following IVF or CA. In addition, ROS generation in cleaved embryos was related to cleavage rate depending on the antioxidant used.

Namely, $\beta-\mathrm{ME}$ and MEMv treatment during oocyte maturation increased cleavage formation in IVF and CA by reducing ROS generation of cleaved embryos while a single antioxidant did not show a constant effect on cleavage formation in relation to ROS. Researchers suggest that the combination of $\beta-\mathrm{ME}$ and MEMv might be more effective for in vitro maturation of porcine oocytes which are to be used for IVF or CA. It has been reported that the presence of $\beta-\mathrm{ME}$ in IVM media enhances the intracellular GSH concentration in embryos and improves in vitro fertilization (Nagai, 2001; De Matos et al., 2002; Takahashi et al., 2002). Vitamin B6 and niacin in MEMv have been reported to reduce the level of ROS (Kamat and Devasagayam, 1996; Kannan and
Jain, 2004). Researchers speculate that $\beta$-ME addition to the IVM medium supplemented with MEMv might have contributed to reduce ROS by producing GSH and improve cleavage formation in the present study. On the other hand, cleavage rates of oocytes following EA were not influenced by antioxidants although, ROS generation in cleaved embryos was significantly reduced by $\beta-\mathrm{ME}$ and MEMv compared to treatment with a single antioxidant. In electrical activation, an electric pulse induces temporary pore formation in the mammalian oocyte membrane. When $\mathrm{Ca}^{2+}$ ions are present in the pulsing medium, an influx of $\mathrm{Ca}^{2+}$ occurs through the temporary pore (Sun et al., 1992). Calcium ion concentrations present in pulsing medium affected ROS generation (Lee et al., 2005; Miyoshi et al., 2005). Koo et al. (2008) indicated that electrical activation induced ROS in porcine embryos and generation of ROS should be considered for optimizing electrical activation. Researchers infer that oxidative stress by ROS upon electrical activation might be more severe compared to in vitro fertilization and chemical activation and may be an obstacle to subsequent embryonic development of electrically activated oocytes.

The relationship between cleavage rate and ROS generation in cleaved embryos subsequently influenced blastocyst formation and blastocyst apoptosis. Yang et al. (1998) suggested that ROS are a detriment to embryo development causing apoptosis. In this study, the combination use of $\beta-\mathrm{ME}$ and MEMv supplemented into maturation medium improved the rate of blastocyst formation by reducing apoptosis during IVF and CA. Addition of $\beta-\mathrm{ME}$ and MEMv during oocyte maturation may enhance normal embryo development by suppression of ROS concentration and apoptosis level in embryos. However, single use of $\beta$-ME or MEMv showed blastocyst rates similar to the absence of antioxidant. Percentages of TUNEL-positive nuclei were not significantly decreased in either group. Kobayashi et al. (2006) demonstrated $\beta$-ME supplemented into maturation medium did not improve blastocyst formation after Intracytoplasmic Sperm Injection (ICSI).

However, $\beta-\mathrm{ME}$ treatment during in vitro maturation increased blastocyst formation following IVF (Han et al., 2003). Naruse et al. (2007) demonstrated that MEMv during IVM increased 
blastocyst rate following parthenogenetic activation. The results of the studies mentioned above cannot be directly compared to the results due to the variety of concentrations and antioxidants as well as the use of different oocyte manipulation methods after antioxidant treatment. However, the combination of $\beta-\mathrm{ME}$ and $\mathrm{MEMv}$ in the present study produced a constant effect on blastocyst formation as well as cleavage formation in both IVF and CA. Overall, the capacity of a single antioxidant such as MEMV or $\beta-M E$ might be limited compared to the combination of $\beta-\mathrm{ME}$ and MEMv. The level of ROS in oocytes activated electrically following $\beta-\mathrm{ME}$ and MEMv treatment during IVM was significantly reduced at an early embryo stage although, the level of apoptosis was not significantly decreased in late stage embryos. Researchers suspect that the antioxidants added during maturation might be consumed to reduce many ROS generated in early stage embryos by electrical activation compared to IVF and CA. As a result, the combination use of $\beta-\mathrm{ME}$ and $\mathrm{MEMv}$ might not improve late stage embryonic development in electrically-activated oocytes. In a future study, researchers might consider a higher concentration of $\beta-\mathrm{ME}$ and MEMv or another effective antioxidant that might improve blastocyst formation by decreasing $\operatorname{ROS}$ and preventing apoptosis due to electrical activation.

Kobayashi et al. (2006) reported that the cell number of porcine blastocysts produced by ICSI was not increased by $\beta-\mathrm{ME}$ treatment. MEM vitamins also did not affect cell number of porcine blastocysts (Naruse et al., 2007). In the present study, no antioxidants improved blastocyst cell numbers. Researchers suggest that antioxidant supplementation during oocyte maturation might not affect embryo mitosis following blastocyst formation.

\section{CONCLUSION}

In this study, the combination use of $\beta$-ME and MEMv during oocyte maturation improved embryonic development from oocytes fertilized in vitro or activated chemically by alleviating ROS generation and apoptosis.

Researchers suggest that the synergistic effect of $\beta-\mathrm{ME}$ and MEMv during IVM of porcine oocytes may help to improve the sub-optimal conditions within in vitro culture systems.

\section{REFERENCES}

Abeydeera, L.R. and B.N. Day, 1997. Fertilization and subsequent development in vitro of pig oocytes inseminated in a modified tris-buffered medium with frozen-thawed ejaculated spermatozoa. Biol. Reprod., 57: $729-734$.
Aitken, R.J., D. Harkiss and D. Buckingham, 1993. Relationship between iron-catalysed lipid peroxidation potential and human sperm function. J. Reprod. Fertil., 98: 257-265.

Am-in, N., R.N. Kirkwood, M. Techakumphu and W. Tantasuparuk, 2011. Lipid profiles of sperm and seminal plasma from boars having normal or low sperm motility. Theriogenology, 75: 897-903.

Betts, D.H. and W.A. King, 2001. Genetic regulation of embryonic death and senescence. Theriogenology, 55: 171-191.

Bormann, C.L., E.M. Ongeri and R.L. Krisher, 2003. The effect of vitamins during maturation of caprine oocytes on subsequent developmental potential in vitro. Theriogenology, 59: 1373-1380.

Choe, C., Y.W. Shin, E.J. Kim, S.R. Cho and H.J. Kim et al., 2010. Synergistic effects of glutathione and $\beta$ mercaptoethanol treatment during in vitro maturation of porcine oocytes on early embryonic development in a culture system supplemented with L-cysteine. J. Reprod. Dev., 56: 575-582.

Cui, X.S. and N.H. Kim, 2005. Polyamines inhibit apoptosis in porcine parthenotes developing in vitro. Mol. Reprod. Dev., 70: 471-477.

De Lamirande, E., H. Jiang, A. Zini, H. Kodama and C. Gagnon, 1997. Reactive oxygen species and sperm physiology. Rev. Reprod., 2: 48-54.

De Matos, D.G., B. Gasparrini, S.R. Pasqualini and J.G. Thompson, 2002. Effect of glutathione synthesis stimulation during in vitro maturation of ovine oocytes on embryo development and intracellular peroxide content. Theriogenology, 57: 1443-1451.

Forrest, V.J., Y.H. Kang, D.E. McClain, D.H. Robinson and N. Ramakrishnan, 1994. Oxidative stress-induced apoptosis prevented by Trolox. Free Radic. Biol. Med., 16: 675-684.

Franco, R. and J.A. Cidlowski, 2009. Apoptosis and glutathione: Beyond an antioxidant. Cell Death Differ., 16: 1303-1314.

Gardner, D.K., M. Lane, A. Spitzer and A. Batt, 1994. Enhanced rates of cleavage and development for sheep zygotes cultured to the blastocyst stage in vitro in the absence of serum and somatic cells: Amino acids, vitamins and culturing embryos in groups stimulate development. Biol. Reprod., 50: $390-400$.

Gil, M., C. Alminana, C. Cuello, I. Parrilla, J. Roca, J.M. Vazquez and E.A. Martinez, 2007. Brief coincubation of gametes in porcine in vitro fertilization: Role of sperm: Oocyte ratio and postcoincubation medium. Theriogenology, 67: 620-626.

Gil, M.A., C. Cuello, I. Parrilla, J.M. Vazquez, J. Roca and E.A. Martinez, 2010. Advances in swine in vitro embryo production technologies. Reprod. Dom. Anim., 45: 40-48. 
Han, M.H., K.B. Lee, H.S. Cheon, B.K. Park, K.W. Seo and K.S. Lee, 2003. Effect of $\beta$-mercaptoethanol on in vitro maturation of porcine follicular oocytes and development of porcine IVM/IVF embryos. Korean J. Anim. Reprod., 27: 125-133.

Hashimoto, S., N. Minami, R. Takakura, M. Yamada, H. Imai and N. Kashima, 2000. Low oxygen tension during In vitro maturation is beneficial for supporting the subsequent development of bovine cumulusoocyte complexes. Mol. Reprod. Dev., 57: 353-360.

Hunter, R.H.F. and T. Greve, 1997. Could artificial insemination of cattle be more fruitful? Penalties associated with aging eggs. Reprod. Dom. Anim., 32: $137-141$.

Kamat, J.P. and T.P. Devasagayam, 1996. Methylene blue plus light-induced lipid peroxidation in rat liver microsomes: Inhibition by nicotinamide (vitamin $\mathrm{B}_{3}$ ) and other antioxidants. Chem. Biol. Interact., 99: 1-16.

Kane, M.T. and B.D. Bavister, 1988. Vitamin requirements for development of eight-cell hamster embryos to hatching blastocysts in vitro. Biol. Reprod., 39: $1137-1143$.

Kane, M.T., 1988. The effects of water-soluble vitamins on the expansion of rabbit blastocysts in vitro. J. Exp. Zool., 245: 220-223.

Kannan, K. and S.K. Jain, 2004. Effect of vitamin $B_{6}$ on oxygen radicals, mitochondrial membrane potential and lipid peroxidation in $\mathrm{H}_{2} \mathrm{O}_{2}$-treated $\mathrm{U} 937$ monocytes. Free Radic. Biol. Med., 36: 423-428.

Kobayashi, M., E.S. Lee and Y. Fukui, 2006. Cysteamine or $\beta$-mercaptoethanol added to a defined maturation medium improves blastocyst formation of porcine oocytes after intracytoplasmic sperm injection. Theriogenology, 65: 1191-1199.

Koo, O.J., G. Jang, D.K. Kwon, J.T. Kang and O.S. Kwon et al., 2008. Electrical activation induces reactive oxygen species in porcine embryos. Theriogenol., 70: 1111-1118.

Lee, G.S., H.S. Kim, S.H. Hyun, S.H. Lee and H.Y. Jeon et al., 2005. Production of transgenic cloned piglets from genetically transformed fetal fibroblasts selected by green fluorescent protein. Theriogenology, 63: 973-991.

Levy, R.R., H. Cordonier, J.C. Czyba and J.F. Goerin, 2001. Apoptosis in preimplantation mammalian embryos and genetics. Ital. J. Anat. Embryol., 106: 101-108.

Long, C.R., P. Damiani, C. Pinto-Correia, R.A. MacLean, R.T. Duby and J.M. Robl, 1994. Morphology and subsequent development in culture of bovine oocytes matured in vitro under various conditions of fertilization. J. Reprod. Fertil., 102: 361-369.

Luvoni, G.C., L. Keskintepe and B.G. Brackett, 1996. Improvement in bovine embryo production in vitro by glutathione-containing culture media. Mol. Reprod. Dev., 43: 437-443.
Machaty, Z., B.N. Day and R.S. Prather, 1998. Development of early porcine embryos in vitro and in vivo. Biol. Reprod., 59: 451-455.

Miyoshi, K., Y. Yuki and M. Yoshida, 2005. Optimization of $\mathrm{Ca}^{2+}$ concentrations in fusion and activation media for production of cloned embryos from miniature pig somatic cells. J. Reprod. Dev., 51: 699-706.

Nagai, T., 2001. The improvement of in vitro maturation system for bovine and porcine oocytes. Theriogenology, 55: 1291-1301.

Naruse, K., H.R. Kim, Y.M. Shin, S.M. Chang, H.R. Lee, C.S. Park and D.I. Jin, 2007. Low concentrations of MEM vitamins during in vitro maturation of porcine oocytes improves subsequent parthenogenetic development. Theriogenology, 67: 407-412.

Niwa, K., 1993. Effectiveness of in vitro maturation and in vitro fertilization techniques in pigs. J. Reprod. Fertil. Suppl., 48: 49-59.

Olson, S.E. and G.E. Jr. Seidel, 2000. Culture of in vitroproduced bovine embryos with vitamin $\mathrm{E}$ improves development in vitro and after transfer to recipients. Biol. Reprod., 62: 248-252.

Romar, R. and H. Funahashi, 2006. In vitro maturation and fertilization of porcine oocytes after a $48 \mathrm{~h}$ culture in roscovitine, an inhibitor of $\mathrm{p} 34^{\mathrm{cdc} 2} / \mathrm{cyclin} \mathrm{B}$ kinase. Anim. Reprod. Sci., 92: 321-333.

Sun, F.Z., J. Hoyland, X. Huang, W. Mason and R.M. Moora, 1992. A comparison of intracellular changes in porcine eggs after fertilization and electroactivation. Development, 115: 947-956.

Takahashi, M., T. Nagai, N. Okamura, H. Takahashi and A. Okano, 2002. Promoting effect of betamercaptoethanol on in vitro development under oxidative stress and cystine uptake of bovine embryos. Biol. Reprod., 66: 562-567.

Wang, W. and K. Niwa, 1995. Synergetic effects of epidermal growth factor and gonadotropins on the cytoplasmic maturation of pig oocytes in a serum-free medium. Zygote, 3: 345-350.

Wu, T.W., D.A.G. Mickle and R.D. Weisel, 1990. The cryoprotective effect of Trolox demonstrated with three types of human cells. Biochem. Cell. Biol., 68: 1189-1194.

Yang, H.W., K.J. Hwang, H.C. Kwon, H.S. Kim, K.W. Choi and K.S. Oh, 1998. Detection of Reactive Oxygen Species (ROS) and apoptosis in human fragmented embryos. Hum. Reprod., 13: 998-1002.

Yu, I., N. Songsasen, R.A. Godke and S.P. Leibo, 2002. Differences among $\operatorname{dog} s$ in response of their spermatozoa to cryopreservation using various cooling and warming rates. Cryobiology, 44: 62-78. 